\title{
The influence of financial performance and innovation of services and products on the survival of small businesses in food and beverage in the Jakarta city with mediation of operational improve- ment
}

\author{
Assed Lussak $^{a^{*}}$, Edi Abdurachman ${ }^{a}$, Idris Gautama ${ }^{a}$ and Rini Setiowatia
}

a BINUS University, Indonesia

\begin{tabular}{l}
\hline C H R O N I C L E \\
\hline Article history: \\
Received: July 82019 \\
Received in revised format: July \\
192019 \\
Accepted: August 19, 2019 \\
Available online: \\
August 19, 2019 \\
\hline Keywords: \\
MSMEs \\
Survival \\
Operational Improvement \\
Service Innovation and Products
\end{tabular}

\section{A B S T R A C T}

Small businesses in the food and beverage sector are currently experiencing rapid development, including in Indonesia. Although more and more studies on small businesses occur, but the key factors for companies to survive in a certain period of time - during the last three and a half years in this study, still need to be explored. Especially in Indonesia, small businesses as part of micro, small and medium enterprises (MSMEs) are able to contribute $60.34 \%$ of national Gross Domestic Product (GDP). This research method belongs to the type of explanatory research. Determination of the first level sample uses purposive sampling, namely small businesses engaged in food and beverages, at least 3.5 years old. Based on the analysis it was concluded that the Service Innovation and Product variables had a positive effect on Operational Improvement, Service Innovation and Products had a positive effect on Survival SMEs, Operational Improvement had a positive effect on Survival, Financial Performance had a positive effect on Operational Improvement and Financial Performance had effect on Survival.

(C) 2020 by the authors; licensee Growing Science, Canada

\section{Introduction}

Small businesses in the food and beverage sector are currently experiencing rapid development, including in Indonesia. Unfortunately, many of these small businesses cannot survive for long. Although lower than international standards, the survival rate ratio in Indonesia is only $10 \%$ of the total small business population that appears every year. In Indonesia alone, a 3.5year survival rate is set by the Ministry of Cooperatives and SMEs (KUKM) for someone to be called an entrepreneur. Several other studies also show that only $50 \%$ of small businesses in the United States are able to continue their operations for five years (Julien, 2018; Ripsas et al., 2018). Even outside the United States, only around 33\% survive (Muller et al., 2016). Thus, it becomes important to get a new finding about what factors can encourage the achievement / creation of this survival rate. Speaking about the factors of achieving survival, previous research shows that good corporate performance, especially from the financial side becomes the main prerequisite (Hillary, 2017). But it turns out, outside of financial performance, found a number of influential determinants, functioning as mediation to achieve business survival. The seven determinants are the owner's background, source of funding, ability of employees, relations with customers, service and product innovation, external support, and operational improvement (de Jesus Pacheco et al., 2017). Although these determinants exist, several studies underscore the need for a moderating variable to achieve survival (Nduyu \& Magutu, 2018). This is because even though the determinants above exist, there are still small businesses that do not survive, especially in the field of food and beverages (Hillary, 2017).

\footnotetext{
* Corresponding author.

E-mail address: assedlussakbinus@gmail.com (A. Lussak) 


\subsection{Problem Identification and Formulation}

The scope of further research focuses on small businesses in the food and beverage sector in Indonesia. Although more and more studies on small businesses, but the key factors for companies to survive in a certain period of time still need to be explored. It is important to look at this orientation so that the small company survival rate can continue to be warned. Especially in Indonesia, small businesses as part of micro, small and medium enterprises (MSMEs) are able to contribute $60.34 \%$ of national GDP (Tambunan \& Busnetti, 2018). Small businesses alone account for 31\% of all MSMEs (Nasional, 2016).

Thus, the observation variable in this study raises the following questions:

1. Does Financial Performance have an effect on Operational Improvement?

2. Does Service Innovation and Products have an effect on Operational Improvement?

3. Does Financial Performance Affect Survival Business?

4. Does Operational Improvement affect the Business Survival?

5. Does Service Innovation and Products have an effect on Business Survival?

\section{Literature review}

\subsection{Resource-Based View of the Firm}

Resource-Based View (RBV) has been widely used to study the extent to which companies can gain competitive advantage. This advantage is largely determined by its capacity to spread its resources and capabilities appropriately; which is also rare, valuable, cannot be substituted, and difficult to imitate (Barney \& Mackey, 2016). These resources and capabilities are often seen as tangible and intangible assets consisting of management skills, processes, and company routines, etc. (Barney \& Mackey, 2016). Because the resources and capabilities of various companies are different, the performance of each unit will also be different. Although resources are seen as a collection of factors that are owned and / or controlled by the company, capability is seen as a capacity to disseminate these resources (Amit \& Schoemaker, 1993)

\subsection{Financial Performance, Operational Improvement, and Business Survival}

Research aimed at identifying determinants of business failure was found in six research literature, namely prediction of bankruptcy, company productivity, business demographics, company ecology, personal personality traits, and entrepreneurial research (Barbosa, 2016). In all of these fields, there has been significant progress during the past two and a half decades. This is thanks to the internet, which has facilitated the exchange of experiences between authors, econometric developments regarding panel data analysis, routine computational calculations of correspondent statistics using computer packages of standard and econometric statistics, and increasing researchers' access to public data collections in many countries in the world, except developing countries. However, it is not too difficult to designate research that, after using perceptions, either by means of interviews or data questionnaires have explained several questions related to the sustainability of SME businesses and, in particular, small companies (Barbosa, 2016). One problem with prejudice is that it is a mistake because it cannot find the common thread placed only on the person interviewed or the respondent, but actually, the problem may be in many other phases of the research effort. Another feature of the survey that makes them unacceptable to most types of audience is its small sample size, it seems almost unavoidable because in-depth surveys involve expensive and time-consuming processes and are highly dependent on voluntary cooperation by the company under investigation. However, there is still a rejection of the thoughts mentioned above. Brophy and Shulman (1992) emphasize that there are incentives for small sample studies, they base their statements on two proofs. The first is that promising new publishing directives for financial research seem to be imminent for the 1990s and that three prestigious academic journals have encouraged researchers to spend their efforts on a single case study or clinical study. The second is that changes in publishing policy occur as a result of two conceptual advances. One of them, known as "noise", emerged from criticism of statistical analysis of information provided by large financial databases, which, although believed to be very reliable, appeared to have a deadly trap. Although a long time has passed since the statement of Brophy and Shulman (1992) was made, a literature review of the research conducted in this study has not observed actual changes in research orientation for the acceptance of small sample studies. The same thing - usually for large sample sizes - seems to include research into business survival in the field of small and medium enterprises. Some studies deal with large populations and amazingly take the time to calculate and report statistical significance, while assessing economic significance and examining specification errors seems to be the actual action needed. On the other hand, the nature of small companies - different from big businesses - seems to be more suitable for using interview methods, survey methodologies. According to Barton and Matthews (1989), regarding the tendency of risk and the objectives of top management, subordinates in small companies tend to adopt the employer / owner's decision uncritically, so the possibility arises that only the attitude of the employer needs to be measured to assess management's overall attitude. Still according to them, this contrasts with the case in large companies, where the collective attitude of the dominant coalition must be assessed. The analysis produces evidence that supports many factors that are postulated from the viability of small business enterprises. Most of these determinants are, individually, combined or interacted, elements of the company's daily operations, and, in many cases, according to the amount that is worth keeping under control, after the most profitable number or level of the company is optimal. 
$\mathrm{H}_{1}$ : Financial Performance has a significant positive effect on Operational Improvement.

$\mathrm{H}_{2}$ : Service Innovation and Products have a significant positive effect on Operational Improvement.

$\mathrm{H}_{3}$ : Financial Performance has a significant effect on Business Survival.

\subsection{Product and Service Innovations, Operational Improvement, and Business Survival}

Service product innovation can be defined as the development of new services, which can be either new market offerings or new services for companies or industries (Wang et al., 2015). The dominant way of categorizing innovation and developing typologies for both products and services has to do with the nature of innovation. For example, the level of newness in the company and how much change has been made in the product. Christensen et al. (2018) propose a classification in which service innovations are grouped into radical innovations (including major innovations, pilot / start-up businesses, and new services for the markets currently being served) and additional innovations (including service channel extensions, service improvements, and style changes). Innovation does not only occur in products, but also in processes, and innovation can arise from the merging of processes and products. Wheelwright and Clark (1992) proposed three types of innovation; that is, breakthrough projects (fundamental changes to existing products and processes), platform projects (new product lines), and derivative projects (additional changes to products and processes). Process innovation in manufacturing companies is usually separated from product innovation, while in services, because production and consumption happen simultaneously, product and process innovation is central to service innovation. Zomerdijk and Voss (2011) define service process innovation as either a radical change in the service delivery process that creates a new service experience, or a gradual increase in the existing shipping process that customers consider new. Service process innovation can be a moment to reorganize the service delivery process which leads to new ways to meet customer needs (Chesbrough, 2010). Service processes include those that are part of the delivery / delivery process and which they can be seen as a back-office process that supports the front-end process. The categorization of service innovation modes has shifted from focusing on product innovation to examining product and process innovations. Some studies thus consider innovation into service processes as a mode of taxonomy of service innovation (Droege et al., 2009). Recently, it has been suggested that there is a third important mode: business model innovation. This is often considered influential in the industrial revolution, in the creation of new markets, and in the transformation of companies (Kindström \& Kowalkowski, 2014). Apple's huge success in revolutionizing the portable entertainment industry and the cellular telecommunications industry can be seen largely due to the successful combination of iPhone / iPad / iPod with its iTunes Store in the business model. Competitors may find it more difficult to replicate or replicate an entire system of activities than a single product or process because business model innovations can create switching costs or increase incentives for participants to transact and remain in the activity system (Amit \& Zott, 2012). Companies commercialize new ideas and technologies through their business models. Every company has a business model, no matter whether they articulate it or not, because the business model determines the value and value propositions forming a company, with a range of activities from the procurement of raw materials to satisfying consumers, in some parts allowing companies to make a profit (Chesbrough, 2007) Chesbrough and Rosenbloom (2002) argue that business models contain six parameters: value propositions, market segments, value chain structures, income mechanisms, company positions in value networks, and competitive strategy formulation where companies that innovate will gain and have advantages over their competitors. Business model innovation is at the heart of change innovation in a company (Markides, 2006). Zomerdijk and Voss (2011) define business model innovation as a substantial or even a whole change in how to earn profits and income, which is often accompanied by innovation in corporate settings to accommodate changes in the business model. Previous research literature shows that there is no design of a particular business model that outperforms others, while various business models can create financial results that are equally solid if they fit the business context (Nenonen \& Storbacka, 2009).

$\mathrm{H}_{4}$ : Operational Improvement has a significant positive effect on Business Survival.

$\mathrm{H}_{5}$ : Service Innovation and Products have a significant positive effect on Business Survival.

\section{Research Methods}

This research is a type of research that uses a quantitative approach. Borrego et al. (2009) state that a quantitative approach is a research approach that primarily uses the post-positivist paradigm in developing science (such as thinking about cause and effect, reduction to variables, hypotheses, and specific questions, using measurement and observation, or testing theory) and uses research strategies such as experiments and surveys that require statistical data. However, if viewed based on its purpose, this research belongs to the type of explanatory research.

\section{Population}

Population is a generalization area consisting of objects or subjects that have certain qualities and characteristics determined by researchers to be studied and then conclusions drawn. According to Baayen et al. (2008), the population is a combination of all elements in the form of events, things or people by having similar characteristics, and being the center of attention of a researcher because it is seen as a research universe. Sampling used in this study belongs to a non-probability sampling technique. Research then uses multi-stage sampling to determine the number of samples, according to the restrictions that exist in the population. Determination of the first level sample uses purposive sampling, namely only small businesses engaged in 
food and beverages, at least 3.5 years old. Physical and online questionnaires will be provided to fill in. Each business unit can only fill one time, with the resource person represented by the owner or person in charge of the business.

\section{Result Analysis}

\subsection{Demographic respondent}

Based on the data above, the number of male respondents was $71(44.3 \%)$, and there were 89 women $(55.6 \%)$. Based on the type of business, most respondents ran businesses include: selling Fried chicken 10 people (6.25\%), geprek chicken 25 people (15.63\%), Martabak 13 people (8.12\%), Thai Tea 12 people ( $7.5 \%), 18$ durian soup $(11.2 \%)$, Café 20 people (12.50\%), Fried tofu 21 people (13.12\%), Meatballs and chicken noodles 23 people $(14.37 \%)$, and chicken and goat satay 18 people (11.25\%). The respondents also asked about their age and education. 38 people $(23.75 \%)$ aged $25-30$ years old, 33 people $(20.62 \%)$ aged $30-35$ years old, 34 people $(21.25 \%)$ aged $35-40$ years old, 27 people (87\%) aged $40-45$ years old, 14 people $(8.75 \%)$ aged 45-50 years and 14 people (8.75\%) aged at least 50 years old. While based on the level of educational background, respondents reported that 9 people $(56.25 \%)$ only finished high school level and 114 people $(71.25 \%)$ hold Bachelor degrees of science. Fig. 1 shows the results of our survey using structural equation modeling.

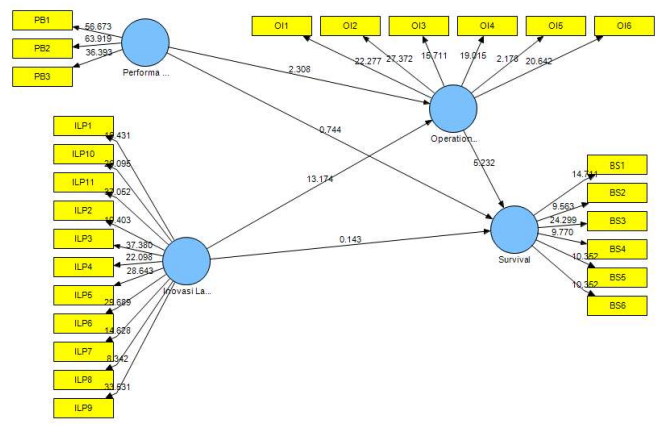

Fig. 1. The results of testing the hypotheses of the survey using SEM method

\subsection{Validity and Reliability Test}

In this study, we conducted a validity test to separate invalid statement items from valid statement items to obtain test results with all $r>r$-table values (with $\mathrm{df}=160-2=158$ and $5 \%$ significance of 0.155 ) and found that all question items are statistically valid. We also tested the reliability level by looking at the Cronbach Alpha values. The results have shown that all variables (including latent variables) $>0.6$. This value means that all variables are very reliable.

Table 1

Evaluation of Measurement Models

\begin{tabular}{llll}
\hline & Cronbachs Alpha & & \\
\hline Product and Service Innovations & 0.933489 & Product and Service Innovations & 0.943610 \\
Operational Improvement & 0.740909 & Operational Improvement & 0.834648 \\
Financial Performance & 0.865841 & Financial Performance & 0.917781 \\
Survival & 0.818599 & Survival & 0.864676 \\
\hline
\end{tabular}

Based on Table 1, we obtain information that the Composite Reliability values in all indicator blocks have met the assumption of Composite Reliability $(>0.6)$ which means that all indicators on each latent variable had adequate consistency. Because the validity is adequate, we state that our model achieves convergence conditions and that external output contains all indicators meeting the assumption of convergence validity. This shows that all indicators in latent variables are divergence to explain the quality of the construct. The discriminant validity of the indicator can be seen in cross loading between indicators and their latent variables.

\subsection{Structural Model Evaluation}

Based on the results of the analysis obtained from $\mathrm{R} 12=0.633$, it means that the latent variables of Service and Product Innovation can be well explained by Operational Improvement $63.3 \%$ with R22 $=0.431$. This means that the latent variable Financial Performance can be explained by Survival at $65.6 \%$.

\subsection{Hypothesis testing}

Before the hypothesis test a bootstrap procedure was performed on the sample data. Bootstrap is performed 300 times where in every bootstrap data is done, resampling is obtained as many as 160 valid data. The bootstrap result with a bootstrap sample 
is 300 times assumed that the data has a normal distribution so that the parameter test in the model can be done with the $t$ test. The coefficient value of the structural model is said to be significant if $t$ count $>t$-table is 1.96 (1.96 is the value of t-table at the confidence level of $95 \%$ ). The results of hypothesis testing for external models conclude that all significant indicators are used to construct the model while the results of the hypothesis testing in the model can be seen in Table 2 with the results of all significant path coefficients.

Table 2

$\underline{T}$ test for path coefficient

\begin{tabular}{|c|c|c|c|c|c|}
\hline & $\begin{array}{l}\text { Original } \\
\text { Sample (O) }\end{array}$ & $\begin{array}{l}\text { Sample } \\
\text { Mean (M) }\end{array}$ & $\begin{array}{l}\text { Standard } \\
\text { Deviation } \\
\text { (STDEV) }\end{array}$ & $\begin{array}{l}\text { T Statistics } \\
(|\mathrm{O} / \mathrm{STDEV}|)\end{array}$ & P Values \\
\hline Service and Product Innovation $\rightarrow$ Operational Improvement & 0.9590 & 0.9525 & 0.0762 & 13.173 & 0.024 \\
\hline Product and Service Innovation $\rightarrow$ Survival & 0.5607 & 0.5673 & 0.1218 & 4.5291 & 0.018 \\
\hline Operational Improvement $\rightarrow$ Survival & 0.6144 & 0.6167 & 0.1173 & 5.2316 & 0.017 \\
\hline Financial Performance $\rightarrow$ Operational Improvement & -0.2056 & -0.1909 & 0.0947 & 2.3075 & 0.044 \\
\hline Financial Performance $\rightarrow$ Survival & -0.1239 & -0.1217 & 0.0267 & 1.1939 & 0.026 \\
\hline
\end{tabular}

Source: author

Based on the table above, it can be found that Service Innovation and Product variables have a significant effect on Operational Improvement with P value 0.024, Service Innovation and Product variables have a significant effect on Survival with P value 0.018, Operational Improvement variable has a significant effect on Survival with P Value 0.017, Financial Performance Variable significant effect on Operational Improvement with a P value of 0.044, and the Financial Performance variable has significant effect on Survival with a P value of 0.026.

\subsection{Discussion}

Variable Service and Product Innovations have a significant effect on Operational Improvement, which can be seen from the results of the analysis with a $p$ value of 0.024. In addition, the results of Yeh-Yun Lin and Yi-Ching Chen (2007) show that the effect of Service and Product Innovation practices on Operational Improvement strengthened in several SMEs. The effects of Service and Product Innovation practices on Operational Improvement weakened in some SMEs when there was a higher level of environmental uncertainty. Based on the results, this study has implications for Service Innovation and Products can encourage and maintain Operational Improvement that results in a sustainable competitive advantage. Variable Service Innovation and Product significant influence on Survival, which can be seen from the results of the analysis with $\mathrm{p}$ value 0.018 . This study investigates how product innovation, as a strategy, increases the survival of small and medium enterprises in Nigeria, using Prodco Foods Nigeria Limited as a study. Among the objectives set are the relationship between product innovation and the survival of Small and Medium Enterprises (SMEs), changes in tastes and preferences of consumers who need product innovation, and whether product innovation increases the sales volume of SMEs. This finding reveals that there is a significant relationship between product innovation and the survival of SMEs, also, that changes in consumer tastes and preferences require product innovation, and that product innovation increases the sales volume of SMEs.

Variable Operational Improvement has a significant effect on Survival, which can be seen from the results of the analysis with a value of $\mathrm{p}$ 0.017. this research provides an understanding to SME owners and managers in Malaysia about the influence of Operational Improvement to improve their Survival principles which leads to achieving operational excellence in their business. Furthermore, this research is expected to bring new understanding to managers and stakeholders along with various factors related to increasing Survival of SMEs. This study is significant because of the need to investigate elements in management and beyond management's control and their influence on increasing Survival of SMEs in developing countries. Financial Performance has a significant effect on Operational Improvement, which can be seen from the results of the analysis with a $\mathrm{p}$ value of 0.044 . The study by Mjongwana and Kamala (2018) provides useful information about the use of Financial Performance which can be used by the Small Business Development Department to inform the development of Operational Improvement that aims to reduce the failure of SMEs. This finding can also help SMEs increase their use of Financial Performance to take advantage of the benefits gained from using these steps. In addition, these findings can help SMEs overcome the factors that prevent them from using Financial Performance and direct them to more efficient operations. Financial Performance Variables have significant effect on Survival, which can be seen from the results of the analysis with a value of $p$ 0.026. Rajan (2006) states that financial stability risk can cause large financial losses that have a direct or indirect impact on organizational financial stability which results in failure to achieve stated organizational goals and financial goals. The European Federation of Accountants (2004) states that in the case of micro and small businesses (with a number of employees under 50 employees), the risk of bankruptcy increases significantly when the entrepreneur has insufficient technical and practical expertise to monitor the financial performance of the business, or does not have enough time to do it.

\section{Conclusions and Suggestions}

Based on the analysis and discussion it has been concluded that the Service Innovation and Product variables had a positive effect on Operational Improvement, Service Innovation and Products had a positive effect on Survival SMEs, the variable Operational Improvement had a positive effect on Survival, Financial Performance had a positive effect on Operational Improvement, Financial Performance had effect on Survival. Because of the increasing number of failure rates of death and the 
need for sustainability of SMEs, the need to investigate operations management among SME entrepreneurs must be an important field to learn. This is because, the operation function is one of the important functional areas that will affect the sustainability of SMEs. Based on the results, this study has implications for Service Innovation and Products can encourage and maintain Operational Improvement that results in a sustainable competitive advantage. Although the two determinants exist, several studies underscore the need for a moderating variable to achieve survival. This is because it turns out even though the determinants above exist, there are still small businesses that do not survive, especially in the field of food and beverages. But it should be noted, the moderating variable sought, must be continuous in supporting determinant influences.

\section{References}

Amit, R., \& Zott, C. (2012). Creating value through business model innovation. MIT Sloan Management Review, 53(3), 41-49.

Amit, R., \& Schoemaker, P. J. (1993). Strategic assets and organizational rent. Strategic Management Journal, 14(1), 33-46.

Baayen, R. H., Davidson, D. J., \& Bates, D. M. (2008). Mixed-effects modeling with crossed random effects for subjects and items. Journal of memory and language, 59(4), 390-412.

Barbosa, E. (2016). Determinants of Small Business Survival: The Case of Very Small Enterprises of the Traditional Manufacturing Sectors in Brazil. Available at SSRN 2802706.

Barney, J. B., \& Mackey, A. (2016). Text and metatext in the resource-based view. Human Resource Management Journal, 26(4), $369-378$.

Barton, S. L., \& Matthews, C. H. (1989). Small firm financing: Implications from a strategic management perspective. Journal of Small Business Management, 27(1), 1.

Borrego, M., Douglas, E. P., \& Amelink, C. T. (2009). Quantitative, qualitative, and mixed research methods in engineering education. Journal of Engineering Education, 98(1), 53-66.

Brophy, D. J., \& Shulman, J. M. (1992). A finance perspective on entrepreneurship research. Entrepreneurship Theory and Practice, 16(3), 61-72.

Chesbrough, H. (2007). Business model innovation: it's not just about technology anymore. Strategy \& leadership, 35(6), 12-17.

Chesbrough, H. (2010). Open services innovation: Rethinking your business to grow and compete in a new era. John Wiley \& Sons.

Chesbrough, H., \& Rosenbloom, R. S. (2002). The role of the business model in capturing value from innovation: evidence from Xerox Corporation's technology spin-off companies. Industrial and Corporate Change, 11(3), 529-555.

Christensen, C. M., McDonald, R., Altman, E. J., \& Palmer, J. E. (2018). Disruptive Innovation: An Intellectual History and Directions for Future Research. Journal of Management Studies, 55(7), 1043-1078.

de Jesus Pacheco, D. A., Carla, S., Jung, C. F., Ribeiro, J. L. D., Navas, H. V. G., \& Cruz-Machado, V. A. (2017). Eco-innovation determinants in manufacturing SMEs: Systematic review and research directions. Journal of Cleaner Production, 142, 2277-2287.

Droege, H., Hildebrand, D., \& Heras Forcada, M. A. (2009). Innovation in services: present findings, and future pathways. Journal of Service Management, 20(2), 131-155.

Hillary, R. (Ed.). (2017). Small and medium-sized enterprises and the environment: business imperatives. Routledge.

Julien, P. A. (2018). The state of the art in small business and entrepreneurship. Routledge.

Kindström, D., \& Kowalkowski, C. (2014). Service innovation in product-centric firms: A multidimensional business model perspective. Journal of Business \& Industrial Marketing, 29(2), 96-111.

Markides, C. (2006). Disruptive innovation: In need of better theory. Journal of Product Innovation Management, 23(1), 19-25.

Mjongwana, A., \& Kamala, P. N. (2018). Non-financial performance measurement by small and medium sized enterprises operating in the hotel industry in the city of Cape Town. African Journal of Hospitality, Tourism and Leisure.

Muller, P., Devnani, S., Julius, J., Gagliardi, D., \& Marzocchi, C. (2016). Annual report on European SMEs 2015/2016-SME recovery continues. Contract number: EASME/COSME/2015/012]. European Union.

Nasional, B. P. P. (2016). Masterplan Arsitektur Keuangan Syariah Indonesia. Jakarta: BAPPENAS.

Nduyu, D. G. M., \& Magutu, P. O. (2018). Operations Management Practices and Operational Performance of Insurance Brokers in Nairobi City, Kenya. Noble International Journal of Business and Management Research, 2(9), 70-83.

Rajan, R. G. (2006). Has finance made the world riskier?. European Financial Management, 12(4), 499-533.

Ripsas, S., Schaper, B., \& Tröger, S. (2018). A startup cockpit for the proof-of-concept. Handbuch Entrepreneurship, 1-17.

Storbacka, K., \& Nenonen, S. (2009). Customer relationships and the heterogeneity of firm performance. Journal of Business \& Industrial Marketing, 24(5/6), 360-372.

Tambunan, T., \& Busnetti, I. (2018). Small Business Use of the Internet: Findings from Indonesia. Asian Journal of Agricultural Extension, Economics \& Sociology, 1-15.

Wang, Q., Voss, C., Zhao, X., \& Wang, Z. (2015). Modes of service innovation: a typology. Industrial Management \& Data Systems, 115(7), 1358-1382.

Wheelwright, S. C., \& Clark, K. B. (1992). Revolutionizing product development: quantum leaps in speed, efficiency, and quality. Simon and Schuster.

Yeh-Yun Lin, C., \& Yi-Ching Chen, M. (2007). Does innovation lead to performance? An empirical study of SMEs in Taiwan. Management Research News, 30(2), 115-132.

Zomerdijk, L. G., \& Voss, C. A. (2011). NSD processes and practices in experiential services. Journal of Product Innovation Management, 28(1), 63-80.

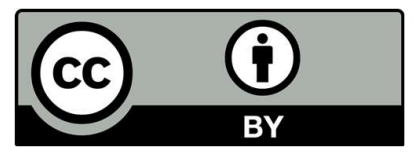

(C) 2020 by the authors; licensee Growing Science, Canada. This is an open access article distributed under the terms and conditions of the Creative Commons Attribution (CCBY) license (http://creativecommons.org/licenses/by/4.0/). 